\title{
As temporalidades recuadas e sua contribuição para a aprendizagem histórica: o espaço como fonte para a História Antiga e Medieval
} The earliest temporalities and their contribution to Historical learning: space as a source for Ancient and Medieval History

Claudia Regina Bovo*

Alex Degan ${ }^{\star *}$

\section{Resumo}

A necessidade de discutir quais são os conhecimentos históricos necessários e apropriados para as gerações que hoje frequentam as escolas tem norteado o desenvolvimento de pesquisas acadêmicas em torno da relação entre a formação da consciência histórica, a construção da competência narrativa em história e a aprendizagem histórica. Com base na reflexão sobre os exercícios de periodização em história, pretendemos delimitar as particularidades que tornam os campos da História Antiga e da História Medieval indispensáveis para a aprendizagem histórica na Educação Básica Brasileira. Mas como o trato com temporalidades tão recuadas pode nos ajudar a aprimorar a

\section{Abstract}

The necessity of discussing what are the needed and appropriated historical knowledges to the generations that today attend school have stated the development of academic researches encompassing the relationship among historical consciousness, narrative competence construction and historical learning process. Based on the reflection about exercises of periodization in history, we intend to limit the particularities that make the fields of Ancient and Medieval History meaningful to the historical learning in the Brazilian Basic Education. But how early temporalities can help us to improve the history learning process? The answer to this question is not sim-

\footnotetext{
* Doutora em História pela Universidade Estadual de Campinas (Unicamp). Professora de História Medieval no Departamento de História, Universidade Federal do Triângulo Mineiro (UFTM), e do Mestrado Profissional em História Ibérica, Universidade Federal de Alfenas (Unifal). Uberaba, MG, Brasil. claubovo@yahoo.com

** Doutor em História Social pela Universidade de São Paulo (USP). Professor no Departamento de História, Universidade Federal do Triângulo Mineiro (UFTM), e pesquisador do Laboratório de Estudos sobre o Império Romano (Leir). Uberaba, MG, Brasil. alexdegan@yahoo.com.br
} 
aprendizagem da história? A resposta a essa questão não é simples. Ela demanda reflexão sobre as formas de definir e usar as fontes nesses campos de investigação. Palavras-chave: ensino; História Antiga; História Medieval. ple. It demands reflections about the ways of defining and using historical sources in the investigation field.

Keywords: teaching; Ancient History; Medieval History.

A necessidade de discutir quais são os conhecimentos históricos necessários e apropriados para as gerações que hoje frequentam as escolas tem norteado o desenvolvimento de pesquisas há longo tempo (Laville, 1999). Nos últimos 40 anos surgiram diversos estudos sobre a realidade educacional brasileira, as deficiências de seu sistema educativo, as políticas públicas implementadas e revistas na tentativa de enquadrar o conjunto da educação básica em posições mais bem ranqueadas nos índices de desenvolvimento humano. Nesse sentido, há pelo menos três décadas o debate em torno das especificidades do ensino de história e suas contribuições para formação intelectual e cidadã têm ocupado lugar de destaque entre professores e historiadores. Para que serve a história na Educação Básica? O que justifica a manutenção da história como disciplina escolar, em tempos nos quais a disponibilidade de história em todo lugar e o interesse por sua vertente científica é cada vez menor? Os autores que discutem a história da educação brasileira defendem que a responsabilidade pelo desinteresse crescente pela história na educação escolar vem, entre muitos fatores, da prática de ensino pouco reflexivo dessa disciplina. Persistimos em ensinar uma história "pronta e acabada", a qual não dialoga com o papel ativo do alunado, que quer participar dos processos de construção do conhecimento.

À medida que aumenta a disponibilidade de história nos meios de comunicação e na sociedade em geral, diminui a crença na capacidade de a história normativa dotar as pessoas de habilidades para a decodificação do mundo. Como já salientou Isabel Barca, o desinteresse pela história vem normalmente por se ignorar seu processo de constituição (Barca, 2007). Ou seja, enquanto persistirmos em associar à história disciplinar a ideia de uma narrativa contínua de causas e efeitos que deve ser partilhada por um agente do saber (professor) com um número considerável de estudantes que supostamente nada sabem, permaneceremos ignorando seus pressupostos básicos: sua capacidade de ser recontada, refeita e reapropriada. Aquela máxima "quem conta um 
conto, aumenta um ponto" tem valor teórico importante aqui. Ao deixarmos claro para qualquer aprendiz de história que a condição fundante desse conhecimento está na sua reescrita, talvez isso volte a despertar nele o interesse em ser mais que um mero espectador, tornar-se um narrador ativo de qualquer experiência histórica. Por isso o trabalho com fontes no ensino básico de história é tão fundamental. Não apenas desmistifica qualquer narrativa "pronta e acabada" de uma pretensa "história única e verdadeira", como assinala um dos primeiros passos ao entendimento de que esse conhecimento, amplamente reconhecido como científico, tem um processo de produção intelectual que não se reduz a se ter visto ou ouvido falar de alguma coisa.

Aqui apresentamos uma das principais potencialidades do ensino da História Antiga e Medieval, das chamadas temporalidades recuadas, para a educação histórica: sua capacidade de demonstrar os recursos teóricos necessários para se produzir significados históricos que vão além dos sentidos que a memória vivida pode dar. Dito de outra maneira, tanto a História Antiga quanto a História Medieval, entre tantas outras periodizações recuadas, auxiliam a desmistificar o tempo histórico, questionando a forma natural com que se lida com ele. De forma geral, ao tratarem de temporalidades tão recuadas, tanto a historiografia sobre a Antiguidade quanto a historiografia medieval se cercaram de muitas referências para permitir o êxito de suas análises. Nestes exercícios essas ponderações acabaram por explicitar ainda mais o encanto singular da história, ou seja, a sua dimensão diacrônica. Lançando-se em operações sobre um tempo social "que serve de referência comum" (Prost, 2008, p.96) aos múltiplos agrupamentos humanos, os historiadores se valeram de uma variada carta de instruções nesses ofícios: excluindo uma perspectiva teleológica que "no depois, procura a razão do antes" (Prost, 2008, p.104), o tempo deve ser trabalhado tanto em uma classificação cronológica dos acontecimentos quanto em uma periodização capaz de reconhecer articulações pertinentes no fluxo de um processo histórico. Essa experiência do "ser e estar antigo e medieval" nos ajuda a desmistificar o tempo histórico, justamente por demonstrar, recorrendo a essas sociedades cuja alteridade era radical, como o tempo pode ser forjado para enfatizar a ruptura e/ou a continuidade. $\mathrm{O}$ tempo enquanto categoria ordenadora da pesquisa e do ensino de história, enquanto condição que permite a fundamentação singular da história frente às outras ciências humanas (Braudel, 2011), precisa das temporalidades, das cronologias 
que advêm delas e dos ritmos diferentes das durações, para estabelecer suas singularidades e também suas relações com o presente de onde se parte para pensá-las. Esse deve ser, em nosso entendimento, o objeto pedagógico central da história, ou seja, "uma meditação retrospectiva sobre a fecundidade própria do tempo, sobre o que ele faz e desfaz; o tempo, principal ator da história" (Prost, 2008, p.114). Em resumo, trata-se de uma concentração necessária sobre a ação de periodizar o passado, de agir sobre o tempo refletido que, nas palavras de Jacques Le Goff,

justifica-se por aquilo que faz da História uma ciência, não uma ciência exata, indubitavelmente, mas uma ciência social, que se funda em bases objetivas a que chamamos fontes. Ora, aquilo que as fontes nos oferecem se move, evolui: é a história das sociedades em marcha no tempo, dizia Marc Bloch. O historiador precisa dominar o tempo, ao mesmo tempo que se encontra em seu poder, e na medida em que esse tempo muda, a periodização se torna, para o historiador, uma ferramenta indispensável. (Le Goff, 2015, p.132)

O que é relevante nessas temporalidades muito recuadas e muito distantes do "ser" e "estar" contemporâneos não é a busca pelas permanências ou tradições remanescentes por elas produzidas, mas justamente sua condição de demonstrar a alteridade extrema que as sociedades humanas mantiveram e ainda mantêm umas com as outras. Essa respeitável distância, na verdade, apresenta-se com potencial vantagem; John Lewis Gaddis apropriadamente observou que "a experiência direta de eventos não é necessariamente o melhor caminho para entendê-los, porque nosso campo de visão não vai mais além de nossos sentidos imediatos" (Gaddis, 2003, p.18). Assim, para Gaddis, o historiador que maneja objetos com temporalidades longas estaria em "melhores condições" de refletir sobre o passado "pelo simples fato de ter um amplo horizonte" para dissecar. Portanto, "não há História, nem investigação, nem obra, nem ensino, sem nos situarmos no tempo" (Heers, 1994, p.32), sem tomarmos conhecimento daquilo que foi produzido e determinado como passado e que, de certa forma, ajudou a definir por mecanismos de alteridade ou de proximidade as referências que reconhecemos como pertencentes ao tempo presente. Mas como o trato com temporalidades tão recuadas pode nos ajudar a aprimorar a aprendizagem da história? A partir de agora discutiremos o 
espaço como fonte para a História Antiga e Medieval, e como esse exercício documental pode auxiliar a habilidade de pensar historicamente.

\section{"COMO FORMIGAS E SAPOS AO REDOR DE UMA POÇA" (Platão, FÉdon, 109B): o Mediterrâneo como EXPERIÊNCIA DOCUMENTAL}

Nas últimas duas décadas pesa sobre a História Antiga uma sólida modificação em suas perspectivas analíticas. Saudável, essa mudança voltou os olhos dos antiquistas ao mar, resumida na bela sentença de Fernand Braudel (2001, p.17): "Sobre o imenso passado do Mediterrâneo, o mais belo testemunho é o próprio mar". Todavia, mais do que o Mediterrâneo propriamente, os historiadores passaram a conferir atenção aos fluxos humanos que cruzaram e cruzam, ainda hoje, suas águas salgadas e mornas. Assim, as terras que bordejam esse velho mar, com suas praias, estreitos, enseadas, penínsulas, penhascos, baías e ilhas, ganham destaque como um belo e estrondoso palco de uma história humana no e do Mediterrâneo (Horden; Purcell, 2000). Tal sutileza vai muito além de um adereço retórico: trata-se da pesquisa das muitas histórias humanas desenroladas no limite das terras e das águas desse mar, como também das múltiplas histórias do Mediterrâneo (Abulafia, 2014), esse imenso mar interno que, no turbilhão de séculos de convivência, moldou e foi moldado pelo Homo sapiens.

As vertentes férteis dessa mudança analítica são inúmeras, mas podem ser agrupadas em três campos inter-relacionados. Fernand Braudel, o eminente historiador francês dos Annales, pode ser, com justiça, apontado como pioneiro nessa mirada mediterrânica. Não por acaso, seu colossal O Mediterrâneo e o Mundo Mediterrâneo na Época de Filipe II abre-se com uma declaração de amor: "Amei apaixonadamente o Mediterrâneo, sem dúvida por ter vindo do Norte, como tantos outros, depois de outros tantos" (Braudel, 2016, p.59). A atenção braudeliana revelou as múltiplas temporalidades dessa história, observando e relacionando tanto os tempos longos das montanhas e das formações da Natureza, quanto os tempos de média e curta durações do desenvolvimento das civilizações, das "prisões mentais" e das atitudes comezinhas da política ordinária. Seu mérito, criticado por muitos (Guriêvitch, 2003, p.95), foi perceber e nos fazer ver essas diversas temporalidades, relacionando-as, bem 
como explicitar a importância cabal da geografia para a história, forjando uma geo-história. No caso específico do Mediterrâneo, Braudel concentrou-se em concebê-lo "como um espaço à mercê de fatores climáticos e geológicos que, em última instância, impõem limites e oferecem possibilidades à ação humana e, consequentemente, às incessantes trocas por vias terrestres e marítimas" (Joly, 2003, p.143), mas sem sucumbir ao pecado geodeterminista. Em suas palavras, "a geografia, neste caso, é um formidável utensílio para explicar, caso não lhe atribuamos um determinismo elementar. Ela clarifica e põe problemas sem, contudo, os resolver. O homem e a história já bastam para complicar e confundir tudo" (Braudel, 2001, p.161).

A segunda vertente encontra-se no bojo das teorias socioambientais, em particular da História Ambiental. Crescente desde o início da década de 1970, atualmente a História Ambiental é um campo vasto e diversificado de pesquisa que focaliza múltiplos aspectos "das interações entre sistemas sociais e sistemas naturais” (Pádua, 2010, p.96), não mais vistos em perspectivas e campos distintos e opostos. Compreendendo a dicotomia homem/cultura versus natureza/ambiente como falsa (Hughes, 1981, p.22), esse campo historiográfico sensibilizou-se com o aprofundamento da história humana, lançada em Eras Geológicas e uma pré-história cada vez mais distantes temporalmente; também se atentou à dimensão ecológica, compreendida não como um lugar, mas como o estudo de inter-relações dos seres bióticos com os ambientes abióticos circundantes, ou seja, com a análise dos ecossistemas gerados por essas relações. Mais do que ocorria com o "ogro da lenda" de Marc Bloch (2001, p.54), aqui o faro da carne humana que guia o historiador deve ser temperado com os odores do campo, das flores, dos minerais, da Natureza. Em suma, a História Ambiental nos alertou para a necessidade de compreendermos que as civilizações fazem parte da Biosfera, elas alteram os ambientes nos quais se criaram e desenvolveram, influindo e também sofrendo influências deles.

Tanto a primeira quanto a segunda vertentes foram manejadas com originalidade no impressionante livro The Corrupting Sea, de autoria dos historiadores britânicos Peregrine Horden e Nicholas Purcell. Os autores lançam mão de um ambicioso recorte cronológico, indo do Paleolítico até a Idade Média, compreendendo nessa longa duração aspectos de uma "unidade na diversidade" que caracterizaria essa história mediterrânica. Ao inaugurar a terceira vertente de abordagem sobre a história do mediterrâneo, tal posição traria a 
vantagem de oferecer uma análise histórica alternativa ao tradicional recorte fornecido pela moldura política e pelo Estado-nação, abordagem bem característica do conhecimento histórico forjado no século XIX e em curso até a Segunda Guerra Mundial. O Mediterrâneo que Horden e Purcell apresentam fundamenta-se em dezenas de microrregiões ecológicas, cada uma delas com suas particularidades climáticas, culturais e agrárias. Essas pequenas regiões, inicialmente isoladas umas das outras, padeceriam de algumas situações comuns e compartilhadas: as chuvas insuficientes para a manutenção de colheitas, produzindo crises periódicas na produção, e o mar Mediterrâneo funcionando como "espaço que ao mesmo tempo divide e une. Fronteira é traço de união, é um 'cimento líquido' que veicula os homens, os produtos e as ideias" (Gras, 1998, p.7). A vital estratégia de sobrevivência dessas microrregiões foi lançada em um longo e lento - mas contínuo - processo de contato, de relacionamentos e de inter-relações facilitado pelo Mediterrâneo (vencida as barreiras tecnológicas e psicológicas da navegação) e pela geografia de suas terras circundantes. As distintas sociedades que bordejavam suas margens estavam integradas em relações de dependência, coexistindo em uma ampla rede de conexões: a conectividade própria desse universo. Essa "connectivity of microregions" (Horden; Purcell, 2000, p.123) caracterizou essa história, compreendendo sua imensa diversidade étnica e cultural dentro dessa dinâmica de trocas que faziam circular produtos, ideias, técnicas e pessoas, conectando as singularidades de uma microrregião à outra. Assim, o "Mar Corruptor" encontraria sua singularidade: tal qual um belo mosaico, o Mediterrâneo seria uma "peça única" composta por inúmeros fragmentos distintos, cada um deles com sua coloração e contorno distintos, mas conectados em seu "cimento líquido". Suas microrregiões ecológicas "não existiam isoladamente, mas no interior de uma teia de relações” (Guarinello, 2013, p.51).

Apesar das críticas (Harris, 2011), acreditamos que essa renovada abordagem possa trazer inúmeras vantagens para o ensino de História Antiga. Em primeiro lugar, ela reforçou a compreensão de que a História Antiga não é a matriz original de nossa época, tampouco uma espécie de "História antiga do Mundo". Tomá-la como "ídolo das origens" do Ocidente é, além de ilusório, insustentável (Guarinello, 2010, p.53). Varrida toda espécie de "lixo tóxico" (Geary, 2005, p.28) que atrelava esses passados aos vícios modernos de nacionalismos e imperialismos, alimentando ideologias que se apropriam e 
pervertem a Antiguidade, a mediterranização da História Antiga desvelou explicitamente sua singularidade: trata-se de uma história particular, localizada no tempo e no espaço, regional e única. Tal perspectiva tratou de recolocá-la dentro de uma História Mundial, não mais como a raiz clássica do Ocidente, mas como uma história importante dentre outras e que ainda nos diz respeito.

Ambientar os alunos com temáticas tradicionalmente próprias da Geografia, relacionando-as com processos históricos, é outra vantagem didática dessa perspectiva. Tomando o espaço como grande mediador das relações entre as duas disciplinas, o desafio é inserir as temporalidades nas paisagens constituindo uma geo-história atenta não apenas aos contornos e acidentes geográficos, mas principalmente aos desafios de se pensar a paisagem como "espaço social", ou seja, um sistema complexo e dinâmico de interações entre fatores bióticos, abióticos e culturais que evoluem em conjunto e com historicidade percebida (Santos, 2008, p.46). Outros conceitos importantes como região, território e fronteira podem funcionar como excelentes instrumentos pedagógicos interdisciplinares para o estudo da Antiguidade.

Outro importante objeto pedagógico reside na atenção gigantesca que a perspectiva de uma História do Mediterrâneo dedicou aos processos de integração engendrados nesse imenso corredor afro-euro-asiático. Esse mar, quase sem marés, com suas dinâmicas e temporadas conhecidas, propiciou um canal adequado para conectar as múltiplas microrregiões. Dentro das embarcações que sulcavam suas águas tépidas era transportada uma miríade de produtos agrícolas e manufaturados: trigo africano e siciliano, vidraria fenícia, cerâmicas áticas, azeite ibérico, artesanato egípcio, garum (molho condimentado de peixes) latino e até mesmo sedas chinesas. O uso de obsidiana fornece impressionantes evidências antigas dessa circulação de produtos. Essa rocha ígnea encontrada no centro da Anatólia e nas ilhas de Melos (Egeu) e Lípara (Tirreno) destaca-se por suas qualidades na indústria lítica: de extração fácil, a obsidiana é simples de lascar, produzindo bordas afiadíssimas. Facas, pontas de flechas e de lanças e uma imensa variedade de lâminas cortantes foram produzidas com esse vidro vulcânico, distribuindo-se por todo o Mediterrâneo Oriental e Ocidental desde o Neolítico (Abulafia, 2014, p.41). Esses pequenos objetos são os testemunhos de uma navegação inicial que conectou comunidades há mais de 10 mil anos. Por volta de 3000 a.C. outro produto se destacou: 
o bronze. Esse metal fundido, produzido com uma liga de estanho e cobre, foi empregado na confecção de armas, adereços e instrumentos de usos variados. O domínio do bronze garantia superioridade bélica e tecnológica. Logo, os centros de mineração de cobre e estanho, bem como as linhas de troca e escoamento desses metais, foram disputados com afinco. No Mediterrâneo Oriental, por exemplo, observamos em 2000 a.C. a consolidação de rotas comerciais duradouras que ligavam todo o Egeu com a Anatólia e o Mar Negro. Posteriormente a mesma movimentação ocorreu em torno do ferro.

Esse crescimento progressivo e lento da inter-relação entre as costas do Mediterrâneo não produziu apenas o interessante intercâmbio de minérios, produtos agrícolas e manufaturados. Pessoas, ideias e culturas circulavam também, o que se atesta pela difusão de técnicas (como as da metalurgia, da arquitetura em pedra, do uso da carroça de guerra) e de estilos que poderíamos chamar de artísticos (pinturas, esculturas e artesanato). Pode-se observar uma lentíssima, mas indelével, difusão da agricultura: partindo do Oriente Médio, com a domesticação de variedades de trigo iniciada por volta de 9500 a.C. (Mazoyer; Roudart, 2010, p.103), ela continuou se irradiando nesse corredor afro-euro-asiático em velocidades distintas. Gordon Childe (1981, p.77), não sem razão, chamou essa transição da predação para a domesticação de plantas e animais de "Revolução Neolítica". A tríade alimentar típica desse Mediterrâneo Antigo floresceu: dourados trigais, longevas oliveiras e ciosos vinhedos testemunham a marcha da agricultura, que aproveitou o aumento de temperatura do Holocênico para se espraiar pelo velho mar. Notamos nesse mesmo processo de difusão transformadora a propagação de sistemas de escrita e de formas de organização política e a circulação de ideias religiosas.

Deve-se ressaltar que tantas movimentações e avanços tecnológicos e culturais se deram em um ambiente inter-relacionado. África, Europa e Ásia estavam conectadas, nutrindo um campo de intercâmbios promovidos pelo Mare Internum. Cidades africanas e médio-orientais como Cartago, Cirene, Hipona, Antioquia, Mênfis, Palmira, Tiro, Jerusalém, Léptis Magna, Biblos e Tingi (Tânger) eram tão importantes quanto Atenas, Corinto, Bizâncio e Roma. Algumas delas, como Alexandria e Babilônia, se consolidaram como gigantescos centros cosmopolitas de comércio, cultura, religiões e política. A Europa do Norte da Britânia, das Gálias e da fronteira Germânica encontrava-se em posição periférica e marginal frente ao mundo mediterrânico. Áreas do 
Centro-Sul da Itália, da Península Balcânica, da Turquia, do Levante, do Egito e da África Magrebina formatavam o núcleo duro dessa História Antiga. Aqui reside uma ambiguidade curiosa e que revela toda sua riqueza pedagógica: uma história projetada, desde o século XIX, para ser a raiz nutriz do Ocidente encontra-se, empiricamente falando, deslocada dessa ideologia (Guarinello, 2010, p.52). Buscar a historicidade desses usos do passado, compreendendo seus processos históricos e seus contextos vinculados, apresenta-se como excelente exercício para auxiliar os discentes a pensarem historicamente.

$\mathrm{Na}$ outra ponta dessa ação figura uma nova visão desse Mediterrâneo Antigo. Antes de estudá-lo de forma compactada, com civilizações se sucedendo quase sempre utilizando molduras políticas próprias das histórias dos Estados Nacionais, o estudante deve ser iniciado em uma abordagem histórica que privilegie o intercâmbio, as trocas e as criações. A História da Grécia Antiga, por exemplo, deixaria de ser um reflexo da narrativa política do Estado-nação (Vlassopoulos, 2007, p.36-63), centrada basicamente em Atenas e Esparta, para se atentar ao fato de que esse "mundo grego" nunca constituiu uma sociedade uniforme, fechada e monolítica. As experiências coloniais helenas atestam bem esse exemplo: assim como os fenícios e, depois, os judeus e romanos, os gregos se espalharam pelo Mediterrâneo e para além dele (Mar Negro, Alto Egito, Norte da Índia, Pérsia). A notável arte Gandhara, que floresceu no século II a.C. em uma região que vai da Ásia Central ao Noroeste da Índia, apresenta este dado singular: o que é grego, indiano ou sírio nessa iconografia? Estudos que abordam as mestiçagens, hibridizações e as interações culturais legitimam essa interpretação (Bancarali Molina, 2008; Momigliano, 1991; Woolf, 1998). Assim, mais do que estudar uma História Antiga estruturada em torno de "uma sucessão cronológica, como se a tocha da História, na corrida de revezamento que é o progresso da Humanidade, tivesse sido transmitida progressivamente do leste para oeste" (Guarinello, 2010, p.52), essa perspectiva aponta para uma leitura condizente com os desafios enfrentados por um mundo cada dia mais conectado e globalizado.

Essa História Antiga ainda nos interessa pela experiência de alteridade e, no mesmo movimento, de intimidade. Quantidades imensas de artigos culturais dialogam cotidianamente com temáticas próprias da Antiguidade, alimentando a consciência histórica dos brasileiros. Da literatura juvenil aos estilos arquitetônicos, dos sermões de líderes cristãos aos gamers e séries do 
momento, os antigos ainda são nossos contemporâneos. Porém, esse é definitivamente outro mundo, e aqui a máxima de David Lowenthal (1998) ganha sentido: "the past is a foreign country". E é dessa estranha intimidade, do trabalho de aproximação entre esses mundos tão distantes, que podemos aprender e ensinar muita coisa. Uma visão mais ampla pode nos auxiliar, por exemplo, na compreensão dos limites e alcances da globalização. As experiências mediterrânicas antigas nos demonstram que tais processos de interação e integração produziram joias inestimáveis, como a Septuaginta (a tradução grega das escrituras sagradas judaicas). Todavia, esse não é um movimento unicamente feliz e positivo em si: os processos de integração nem sempre engendram sociedades mais justas, equilibradas e inclusivas. Muito pelo contrário, eles podem nascer de guerras terríveis ou produzir poderes extraordinários, gigantescos, que retiram e solapam quase todas as margens locais e regionais de intervenção política. O Império Romano também deve ser interpretado como "uma aliança conservadora das elites urbanas com o poder imperial” (Guarinello, 2013, p.143), violento e avassalador. Barcas lotadas de seres humanos - refugiados, mercadores, militares ou turistas - ainda cruzam o Mediterrâneo. As belíssimas ruínas de Palmira não foram dinamitadas pelo Estado Islâmico por acaso. Ponderar sobre essa história ainda nos interessa, ainda nos diz respeito, principalmente para nós que estamos nas margens dos centros do capitalismo moderno.

Por fim, o foco no espaço Mediterrâneo só faz sentido se a atenção se concentrar não no espaço em si, mas nas aventuras humanas ali tramadas. Em um paralelo profundo com os temas contemporâneos da globalização e da mundialização, embebida das temporalidades de Braudel e íntima das análises da História Ambiental, essa nova compreensão da Antiguidade busca reunir multisseculares processos de integração humana em volta desse mar interno. Não se trata, evidentemente, de um espelho geográfico das ideias de helenização e romanização como uma espécie de irresistível pasteurização cultural, mas de processos de integração lentos e profundos, concebidos entre fluxos e refluxos de reações, caminhos alternativos e exclusões. Da domesticação de plantas e animais, passando pelos avanços na mineração e metalurgia, no destacamento da cidade, no advento da escrita e no florescimento de culturas religiosas, o Mediterrâneo Antigo foi uma espécie de "banda larga wireless" que "conectou" civilizações vizinhas em velocidades desiguais, cada uma delas 
voltada para suas pequenas realidades regionais e locais, seus microssistemas-mundo, suas paisagens. E como bem nos ensinou John Gaddis: “Quando pensamos o passado como uma paisagem, a história é o modo pelo qual a representamos, e é este ato de representação que nos diferencia do familiar, deixando-nos vivenciar através de outrem o que não podemos experimentar diretamente: uma visão mais ampla" (Gaddis, 2003, p.19).

Trata-se, portanto, de oferecer uma visão mais dilatada.

\section{O ESPAÇO MEDIEVAL E SEU MANEJO HISTORIOGRÁFICO POR MEIO DE FONTES}

O primeiro exercício metodológico e também teórico feito na investigação em História Medieval é o questionamento das suas fontes de pesquisa. Como elas chegaram até nós? Por que elas chegaram até nós? Quais interesses permitiram sua conservação, sua edição, sua sobrevivência enquanto texto? Em sua maioria, esses textos dizem respeito ao ritmo de conservação e cópia caros às tradições intelectuais pré-iluministas. Das grandes coletâneas do século XIX, tais como a Patrologia Grega e Latina ${ }^{1}$ e a Monumenta Germanea Historica, ${ }^{2}$ aos cartulários ${ }^{3}$ e manuscritos que sobreviveram em bibliotecas monásticas ou públicas, a preocupação dos medievalistas não se restringe apenas à decodificação dos conteúdos desses textos, mas em pensar sobre as razões que permitiram sua sobrevivência contemporaneamente.

Nas últimas décadas do século XX, essa discussão em torno das maneiras de apreender e ler os documentos retomou o centro do debate acadêmico dos estudos medievais. Cientes de que o texto é o resultado de uma escritura, de uma intencionalidade, cuja existência e conservação devem ser questionadas, os medievalistas passaram a pensar o lugar da escrita e seus usos no seio da história social. Considerando o texto não como um espelho da realidade ou como um simples artefato, ele torna-se o vetor principal da produção e da realização de uma morfologia medieval do social, apropriada à observação política e cultural por parte do historiador. Autores como Michel Sot, Anita Guerreau-Jalabert e Jean-Patrice Boudet já afirmaram que "todo medievalista se dedica pouco ou muito a história cultural" (Sot; Guerreau-Jalabert; Boudet, 1998, p.166), sobretudo se considerar os documentos com que trabalha. Essas produções culturais que requerem contextualização e crítica já assinalam a 
profundidade do debate teórico de que os medievalistas precisam dar conta. Da história social à história cultural, esses historiadores partiram atrás de instrumentos que lhes permitissem descobrir nesse objeto "morto", que deixou de ser usado há pelo menos 500 anos, o conjunto de significados do qual foi suporte, já que para nós ele se tornou outro objeto, passível de outros significados.

O exercício de alteridade extrema diagnosticada pela dinâmica das superações e da fundação de novas tradições levou nomes importantes da medievalística contemporânea a reconhecer o quão complexas eram essas sociedades, a ponto de escaparem completamente à nossa compreensão se nos valermos apenas das chaves de leitura de um racionalismo científico para explicá-las. Por essas e outras, neste artigo onde pretendemos tratar sobre diferentes aspectos da história ocidental da noção de espaço, quais características podemos atribuir à Idade Média? Nos últimos anos os medievalistas multiplicaram suas pesquisas sobre a categoria espaço. O interesse pelo estudo dessa temática se deveu em parte ao desenvolvimento da arqueologia medieval e ao campo de pesquisa atribuído a ela, a história da paisagem (Chouquer, 1996). No setor do que chamamos de história religiosa, o interesse pelo estudo do espaço e do território se deu em parte pela preocupação com a temática da peregrinação (García de Cortázar, 1993). Mas apenas no limiar do século XXI sínteses foram produzidas, indicando a centralidade do que consideramos como a categoria geral do espaço para pensar as sociedades medievais (Guerreau, 1996).

Nesse sentido, a primeira observação a se fazer sobre o estudo do espaço e suas variantes na Idade Média é reconhecer a "ausência completa de nossa categoria de espaço no pensamento medieval" (Guerreau, 1996, p.88). Isso porque as sociedades que se constituíram nessa temporalidade eram profunda e radicalmente diferentes das nossas. Em consequência, a maioria das noções que nos servem para qualificar o espaço nas sociedades contemporâneas não são aplicáveis para defini-lo nas sociedades medievais. Na contemporaneidade o espaço apresenta-se como uma realidade inexorável. Nós usamos as coordenadas espaciais para nos localizarmos numa dimensão física inescapável. A existência de coordenadas espaciais tem praticamente um caráter universal. Em qualquer lugar do mundo, em diferentes sociedades atuais, seja naquelas mais old-style ou nas mais hightech, reconhecemos no espaço nossa localização tangível e fazemos uso dele para orientar nossa 
locomoção física. Os mapas, por exemplo, aprendemos a lê-los e interpretá-los com base nas cinco propriedades ordinárias do espaço: o espaço é contínuo, infinito, tem três dimensões, é homogêneo e isotrópico. Ou seja, todos os seus pontos são idênticos entre si, e todas as retas que passam por um mesmo ponto também são idênticas entre si.

Um ponto relevante para se destacar sobre as noções espaciais medievais diz respeito ao uso da palavra espaço. Em seu equivalente latino Spatium é um vocábulo incomum, cuja ocorrência é muito rara nas fontes medievais. Seu significado preciso é o de intervalo, a distância entre dois pontos de referência. A noção base de intermitência entre duas coisas ou pessoas é o único significado possível para esse termo. Ao mesmo tempo o campo semântico latino mostra uma forte presença de vocábulos relativos ao nosso sentido contemporâneo de espaço - locus, via, ascendere, iter e progredi - que não têm nenhuma ligação de sentido direta com seus correspondentes contemporâneos. Tanto lugares quanto edifícios eram evocados dentro de um léxico muito rico. Alain Guerreau (1996; 2001) constatou em seu estudo sobre o campo semântico do espaço uma grande polissemia no vocabulário medieval.

Os termos latinos locus, via, ascendere, iter e progredi, antes de especificarem uma posição geográfica possível no mundo tangível, trazem consigo a dimensão de serem criação de algo sobrenatural. Nesse sentido, as representações do espaço no período são sempre pensadas como posições relativas a alguma coisa, o que dá vazão à polissemia e à multiplicidade de usos vocabulares para esse campo semântico. A categoria espacial não tinha caráter universal, uma vez que Deus, em sua natureza infinita, estava fora e acima das relações espaço-temporais geradas pelo seu próprio ato de Criação. Dessa forma o espaço era caracterizado por ser finito, heterogêneo, polarizado e anisotrópico. Ou seja, comprimento, largura e profundidade não tinham um sentido próprio e não eram intercambiáveis como nosso entendimento dessa categoria. Para delimitar o campo semântico latino do espaço, temos de considerar seus ritmos e flutuações que impedem uma tradução pura e simples daquelas representações nas linguagens contemporâneas. A questão não é traduzir, mas interpretar significados que não estão dados nem conceituados nas nossas práticas linguísticas e muito menos traduzidos em experimentos sociais da nossa atualidade. 
Vejamos o exemplo de uma carta produzida por volta de 1048 por um importante prior da região de Ravena chamado Pedro Damião. ${ }^{4}$ Essa carta foi escrita em forma de tratado e se destinava ao eremita Leão, a quem Damião solicitava auxílio para explicar aos seus eremitas a validade de dizer o "senhor esteja convosco" quando se faz oração solitária na ermida. Nela o prior de Fonte Avellana inicia a exposição sobre a unidade e a universalidade da Igreja, justificando por meio dessa unidade o fundamento para a celebração solitária do ofício divino. Para Damião a sancta ecclesia era antes de tudo a unidade sacramental que, apesar de composta por múltiplas partes físicas identificadas por ele na multiplicidade de seus membros - sacerdos e fidelis - e dos seus edifícios - domus -, está, segundo suas palavras,

fundada em unidade pelo fogo do Espírito Santo, isto porque mesmo quando os lugares concretos parecem dividi-la em partes, o sacramento da unidade íntima não pode ser de forma alguma rompido em sua integridade, porque o amor de Deus foi distribuído em nossos corações pelo Espírito Santo. Assim este Espírito - que é sem dúvida único e múltiplo, um em sua essência divina e múltiplo por seus diversos carismas, encheu a Santa Igreja [assembleia cristã] de seus dons de modo que ela seja uma em todos e toda inteira em suas partes. (Pedro Damião, 1983, p.256).

Enquanto unidade sacramental, a ecclesia é um habitat espiritual e um corpo físico, que tem sua materialidade manifesta na consagração do pão e do vinho e nas inúmeras declarações públicas do texto sagrado. É na ecclesia, vista como um edifício espiritual e físico, que a Lei de Deus está inscrita e deve ser proclamada ao seu auditório. A Santa Igreja não é um lugar, mas um ponto de conexão. Sua consagração permite que a ecclesia efetive-se materialmente, já que pela consagração do pão e do vinho é possível manifestar a unidade sacramental que a compõe,

similarmente como o pão e o vinho se transformam no corpo de Cristo quando alguém o recebe na Igreja [o lugar de culto], como diz Cristo "aquele que come minha carne e bebe meu sangue vive em mim e eu nele", se nós estamos todos no corpo de Cristo, ainda que nos vejamos distintos fisicamente não podemos separar um do outro e em espírito permanecemos Nele. (Pedro Damião, 1983, p.260) 
A proclamação do texto sagrado nos ambientes de celebração coloca esse processo de anúncio e pregação na condição de Livro de Pedra, o locus próprio do retorno à escritura. As concepções eclesiológicas de Damião sobre os lugares de culto aparecem primeiramente nessa carta, conhecida como Dominus Vobiscum (O Senhor esteja convosco), na forma como ele assimila a ação de purificação do Templo interior de cada fiel ao controle dos sacerdotes nos mesmos termos em que purificam o Templo exterior. Na proposta de Pedro Damião a edificação do Templo interior dos eremitas se dá quando, reclusos em suas celas, eles celebram solitariamente o ofício divino, unindo-se assim ao Templo exterior mediante essa proclamação do texto sagrado:

reclusos em nossa solidão física, pode parecer que nós estejamos longe da Igreja [comunidade cristã]; mas, ao contrário, nós estamos bem presentes nela graças ao mistério da unidade indivisível. Nossos santos padres estabeleceram que a relação e a comunhão dos fiéis de Cristo deveriam ser tão certas que as introduziram como símbolo da fé católica, afirmando que devíamos repeti-las entre os primeiros elementos da fé cristã. (Pedro Damião, 1983, p.256)

Numa clara tentativa de reconhecer a presença da unidade sacramental da comunidade cristã nos espaços de desenvolvimento da vida eremítica, onde a reclusão solitária marca o cotidiano de vida, Damião retoma no epílogo que

os irmãos que vivem solitários em suas celas não devem temer o uso da linguagem comum da Igreja, visto que apesar de estarem espacialmente separados da Igreja [assembleia dos fiéis], estão unidos a ela pela caridade, e mesmo não estando fisicamente presentes, eles desfrutam com todos o mistério de sua unidade. (Pedro Damião, 1983, p.272)

Isso porque suas celas são como um templo de Deus, onde o homem recluso na solidão fala secretamente com Deus e apreende o conhecimento mais elevado da verdade. Comparando-a com o sepulcro do Senhor, é nesse lugar físico que o pecado encontra a morte e o Espírito Santo vive em Deus. Sem a cela os irmãos não conseguem inscrever a lei de Deus em seus corações, consequentemente sem um espaço físico de purificação eles não conseguem conceber a Lei de Deus. Ele destaca a centralidade da relação com Deus para definição do lugar das criaturas, determinando a ecclesia, entendida como 
comunidade ou assembleia dos cristãos, fortificada na comunhão dos santos, como a promessa e o meio para a salvação. Os edifícios que abrigavam as relíquias dos santos e onde se celebrava o sacrifício eucarístico definiam assim necessariamente os pontos onde se ancoravam a interioridade no mundo, a parte do spiritus, da onipresença divina que também participa do mundo tangível. Portanto, a oposição entre caro (carne) e spiritus (interioridade): não é a mesma coisa que a oposição usual entre material (real, palpável) e imaterial (algo irreal, não palpável). Uma intenção má que parece algo como um elemento imaterial, no léxico do espaço na Idade Média estava ancorado na carne.

A carta Dominus Vobiscum de Pedro Damião é a primeira de uma série de outras, entre as quais se encontram o liber gratissimus e o De divina Omnipotentia, que visaram definir a ecclesia como um lugar, um espaço material de efetivação da experiência comunitária cristã, seja ela a comunidade secular, composta por fiéis e sacerdotes, seja a comunidade ascética eremítica. Nesse caso, nos lugares de culto são materializados os vínculos sociais que efetivam a unidade sacramental da Igreja, a caridade é o cimento espiritual dessa relação que só se efetiva na celebração do ofício divino e na proclamação da sagrada escritura, ocorram eles num espaço público, como uma igreja secular, ou num lugar recluso, como a cela de uma ermida.

Se à primeira vista Dominus Vobiscum parecia ser uma peça teológica voltada para análise dos usos plurais e singulares no ofício divino, observando cuidadosamente sua estrutura identificamos os objetivos principais do exercício exegético de Damião que se estendem para outros de seus textos: 1. Identificar a sancta ecclesia como a unidade sacramental que reúne fiéis, sacerdotes e edifícios cristãos; 2. Determiná-la como fonte do conhecimento sobre a lei de Deus; 3. Reconhecer a vida eremítica, nas palavras do próprio Damião, como a "escola do aprendizado celeste", como o lugar de "treinamento nas artes de Deus", como ambiente onde o entendimento da lei ocorre de forma simples, mas nem por isso menos válida. Numa relação dialética, como pudemos observar no caso da categoria espacial, exemplo de articulação entre o tangível e o intangível, a pesquisa sobre as sociedades medievais e seu ensino permite que articulemos a profunda alteridade que elas mantêm com as sociedades ocidentais e orientais modernas, ao mesmo tempo que conseguimos identificar como foram matriz constitutiva das últimas. Se considerarmos que os espaços de culto cristão atuais ainda 
carregam esse significado de lugares sagrados, onde o contato com a divindade é privilegiado, perceberemos o quanto as temporalidades recuadas, naquilo que mantemos delas e, principalmente, no que delas nos escapa enquanto experiência social, tornam nossa experiência de "ser" no tempo tão singular. Dessa forma, o recurso às múltiplas temporalidades ainda é essencial ao desenvolvimento do pensamento histórico.

\section{CONSIDERAÇÕES FINAIS}

Vimos até aqui como a História Antiga e a História Medieval podem colaborar significativamente para o redimensionamento do uso de fontes na educação básica, propiciando não apenas novas abordagens, novas formas de problematizar a História disciplinar, constituindo assim novas oportunidades de aprendizagem do pensamento histórico. Dessa forma, pudemos identificar a contribuição cognitiva das temporalidades recuadas para a formação histórica dos jovens. O que é relevante nessas temporalidades muito recuadas como a "Idade Antiga" e a "Idade Média", muito distantes do "ser" e "estar" contemporâneos, não é a busca pelas permanências ou tradições remanescentes por elas produzidas, mas justamente sua condição de demonstrar a alteridade extrema que as sociedades humanas mantiveram e ainda mantêm umas com as outras. Retomamos aqui um dos ensinamentos de Jörn Rüsen a respeito da formação histórica, "ela amplia a orientação histórica por recurso a fatos passados que não se encontram sedimentados nas circunstâncias da vida prática atual. Ela abre o olhar histórico para uma amplidão temporal em que o presente e a história inserida nele são relativizados em contraste com outras histórias" (Rüsen, 2007, p.104).

Se a alteridade pode vir de uma dimensão sincrônica (espacial), é na sua dimensão diacrônica que ela destaca a mudança como elemento primordial da história disciplinar. De certa forma, quando falamos das sociedades antigas e medievais, falamos de uma cultura histórica que ainda nos diz respeito, que ainda nos implica, sobretudo, na definição daquilo que não somos. Por que estudantes se encantam com a fantasia facilmente comercializada sobre essas temporalidades pelos produtos de entretenimento contemporâneo? Se encantam porque esses produtos valorizam aquilo que lhes parece excêntrico nessas sociedades, valorizam aquilo que pelo estranhamento lhes parece muito 
distante da sua realidade. Retomando mais uma vez Rüsen: "o olhar histórico formado, voltado para a alteridade do passado, pode sensibilizar a consciência para a especificidade de seu tempo presente" (Rüsen, 2007, p.113). É justamente a consciência da alteridade que provoca, de maneira complexa, a constituição cognitiva da identidade. Por isso, sem tomarmos conhecimento daquilo que foi produzido e determinado como passado nesse percurso extenso da longa duração corremos o risco de ignorar as referências utilizadas para definir e questionar nossas identidades, corremos o risco de pôr no esquecimento as referências que ainda reconhecemos como "nossas".

\section{REFERÊNCIAS}

ABULAFIA, David. O Grande Mar: uma História humana do Mediterrâneo. Rio de Janeiro: Objetiva, 2014.

BANCALARI MOLINA, Alejandro. ¿Es la "criollización” una alternativa de la romanización? Aevum, Milano: Università Cattolica del Sacro Cuore, v.82, p.199-205, 2008.

BARCA, Isabel. Educação histórica: uma nova área de investigação. Revista da Faculdade de Letras, Porto, Série III, v.2, 2001.

BLOCH, Marc. Apologia da História, ou, O ofício de historiador. Rio de Janeiro: Zahar, 2001.

BRAUDEL, Fernand. História e Ciências Sociais: a longa duração. In: NOVAIS, Fernando A.; SILVA, Rogerio Forastieri da. Nova História em perspectiva. v.1. Propostas e desdobramentos. São Paulo: CosacNaify, 2011.

. O Mediterrâneo e o Mundo Mediterrâneo na Época de Filipe II. v.1. São Paulo: Edusp, 2016.

. Memórias do Mediterrâneo: Pré-História e Antiguidade. Lisboa: Terramar, 2001.

CHASTANG, Pierre. Catulaires, cartularisation et scripturalité médiévale: la structuration d'un nouveau champ de recherche. Cahiers de Civilisation Médiévale, v.49, p.21-31, 2006.

CHILDE, V. Gordon. A evolução cultural do homem. Rio de Janeiro: Zahar, 1981.

CHOUQUER, Gerard. Les formes du paysage. Tome 1. Paris: Errance, 1996.

GADDIS, John Lewis. Paisagens da História: como os historiadores mapeiam o passado. Rio de Janeiro: Campus, 2003. 
GARCÍA DE CORTÁZAR, José Angel; AGUIRRE, Ruiz de. El hombre medieval como "Homo Viator": peregrinos y viajeros. In: SEMANA DE ESTUDIOS MEDIEVALES, 4., 2-6 ago. 1993, Nájera. (José Ignacio de la Iglesia Duarte, coord.). Actas... Logroño: IER, 1994. p.11-30.

GEARY, Patrick J. O Mito das Nações: a invenção do nacionalismo. São Paulo: Conrad, 2005.

GRAS, Michel. O Mediterrâneo Arcaico. Lisboa: Teorema, 1998.

GUARINELLO, Norberto Luiz. História Antiga. São Paulo: Contexto, 2013.

. Uma morfologia da História: as formas da História Antiga. Politeia: História e Sociedade, Vitória da Conquista, v.3, n.1, 2010.

GUERREAU, Alain. L'avenir d'un passé incertain: quelle histoire du Moyen Âge ao XXI siècle? Paris: Seuil, 2001.

Quelques caractères spécifiques de l'espace féodal européen. In: L'ÉTAT OU LE ROI: Les fondations de la modernité monarchique en France (XIV-XVIII siècles). Paris: Maison des Sciences de l'Homme, 1996. p.85-101.

. Il significato dei luoghi nell'Occidente medievale: struttura e dinamica di uno spazio specifico. In: CASTELNUOVO, E.; SERGI, G. (Dir.) Arti e storia nel Medioevo. v.1. Torino: Einaldi, 2002. p.201-239.

GURIÊVITCH, Aaron Y. "Geo-história” e materialismo econômico: Fernand Braudel. In: A síntese histórica e a Escola dos Anais. São Paulo: Perspectiva, 2003.

HARRIS, Willian. O Mediterrâneo e a História Antiga. Mare Nostrum, n.2, p.76-112, 2011.

HEERS, Jacques. A Idade Média, uma impostura. Lisboa: Ed. ASA, 1994.

HORDEN, Peregrine; PURCELL, Nicholas. The Corrupting Sea: A Study of Mediterranean History. Oxford: Blackwell, 2000.

HUGHES, J. Donald. La ecología de las civilizaciones antiguas. México: Fondo de Cultura Económica, 1981.

JABOUILLE, Victor. O Mediterrâneo Antigo: unidade e diversidade. Lisboa: Colibri, 1996.

JOLY, Fábio Duarte. O Mediterrâneo Antigo. In: LOPES, Marcos Antônio (Org.) Fernand Braudel: tempo e história. Rio de Janeiro: Ed. FGV, 2003.

LACOSTE, Yves. A Geopolítica do Mediterrâneo. Lisboa: Edições 70, 2008.

LAVILLE, Christian. A guerra das narrativas: debates e ilusões em torno do ensino de História. Revista Brasileira de História, São Paulo: Anpuh, v.19, n.38, p.125$138,1999$.

LE GOFF, Jacques. A História deve ser dividida em pedaços? São Paulo: Ed. Unesp, 2015. 
LOWENTHAL, David. Como conhecemos o passado. Projeto História, São Paulo: PUC-SP, v.17, p.63-201, nov. 1998.

MAZOYER, Marcel; ROUDART, Laurence. História das agriculturas no mundo: do Neolítico à crise contemporânea. São Paulo: Ed. Unesp, 2010.

MOMIGLIANO, Arnaldo. Os limites da Helenização: a interação cultural das civilizações grega, romana, céltica, judaica e persa. Rio de Janeiro: Zahar, 1991.

PÁDUA, José Augusto. As bases teóricas da história ambiental. Estudos Avançados, São Paulo, v.24, n.68, 2010.

PEDRO DAMIÃO [Petrus Damiani]. Carta 28 (Dominus Vobiscum). In: REINDEL, K. Die Briefe des Petrus Damiani (MGH, Epistolae, II: Die Briefe der deutschen Kaiserzeit, I-IV). v.1, p.248-278, 1983.

PLATÃO. Eutífron, Apologia de Sócrates, Criton, Fédon. Trad. Marcio Pugliesi e Edson Bini. 4.ed. São Paulo: Hemus, 2012.

PROST, Antoine. Doze lições sobre a História. Belo Horizonte: Autêntica, 2008.

RÜSEN, Jörn. História Viva. Teoria da História III: formas e funções do conhecimentos histórico. Brasília: Ed. UnB, 2007.

SANTOS, Milton. Técnica, espaço, tempo: globalização e meio técnico-científico-informacional. São Paulo: Edusp, 2008.

SOT, Michel; GUERRAU-JALABERT, Anita; BOUDET, Jean-Patrice. A Singularidade Medieval. In: RIOUX, Jean-Pierre; SIRINĖLLI, Jean-François (Dir.) Para uma História Cultural. Lisboa: Estampa, 1998.

VLASSOPOULOS, Kostas. Unthinking Greek Polis: Ancient Greek History Beyond Eurocentrism. Cambridge, UK: Cambridge University Press, 2007.

WOOLF, Greg. Becoming Roman: The origins of provincial civilization in Gaul. Cambridge, UK: Cambridge University Press, 1998.

\section{NOTAS}

${ }^{1}$ A Patrologia Grega e a Patrologia Latina fazem parte da Patrologiae Cursus Completus, editada por Jacques Paul Migne entre 1844 e 1866 para subsidiar o estudo do clero. O material está disponível em http://www.documentacatholicaomnia.eu/25_Migne.html.

${ }^{2}$ Os monumentos da história alemã (Monumenta Germaniae Historica) são a tradução literal desse programa editorial que teve seu início em 1819 por iniciativa da Sociedade para o Conhecimento da História Alemã Antiga (Gesellschaft für altere Deutsche Geschichtskunde). De um viés de seleção e salvaguarda dos documentos que faziam referência a um passado remoto alemão, hoje seu objetivo é promover um programa editorial que estabeleça para toda 
a erudição ocidental um padrão de edições críticas. Essas edições, assim como as primeiras do século XIX, estão disponíveis no sítio eletrônico http://www.dmgh.de/.

${ }^{3}$ De acordo com CHASTANG (2006), a história dos cartulários monásticos insere-se numa tentativa de construção da sua memória institucional, como forma de invocar a inserção dessas células cristãs locais no seio da Igreja Universal. Os cartulários aparecem também como material diplomático que alimenta e legitima outros tipos de textos.

${ }^{4}$ Desde que assumiu o priorado de Fonte Avellana em 1043 até sua morte em 1072 Pedro Damião conquistou paulatinamente o status de autoridade eclesiástica, tratando de vários debates teológicos e disputas políticas em seus textos epistolares. Nesse sentido, Dominus Vobiscum é um de seus textos mais comentados e reproduzidos postumamente, o que nos permite cogitar a hipótese da sobrevivência de suas noções de espaço sagrado à posteridade.

Artigo recebido em 4 de maio de 2017. Aprovado em 19 de julho de 2017. 